\title{
Solution for optimal power flow problem in wind energy system using hybrid multi objective artificial physical optimization algorithm
}

\author{
P. Nagaleshmi \\ Panacorp Software Solutions, Nagercoil, India
}

\begin{tabular}{l} 
Article Info \\
\hline Article history: \\
Received Dec 16, 2017 \\
Revised Apr 13, 2018 \\
Accepted Oct 3, 2018 \\
\hline Keywords: \\
Animal migration optimization \\
(AMO) \\
Meta-heuristic algorithms \\
artificial physical optimization \\
(APO) \\
Renewable energy sources \\
optimal power flow (OPF)
\end{tabular}

Article history:

Received Dec 16, 2017

Revised Apr 13, 2018

Accepted Oct 3, 2018

Keywords:

(AMO)

Meta-heuristic algorithms artificial physical optimization

Renewable energy sources optimal power flow (OPF)

\begin{abstract}
Normally, the character of the wind energy as a renewable energy sources has uncertainty in generation. To resolve the Optimal Power Flow (OPF) drawback, this paper proposed a replacement Hybrid Multi Objective Artificial Physical Optimization (HMOAPO) algorithmic rule, which does not require any management parameters compared to different meta-heuristic algorithms within the literature. Artificial Physical Optimization (APO), a moderately new population-based intelligence algorithm, shows fine performance on improvement issues. Moreover, this paper presents hybrid variety of Animal Migration Optimization (AMO) algorithmic rule to express the convergence characteristic of APO. The OPF drawback is taken into account with six totally different check cases, the effectiveness of the proposed HMOAPO technique is tested on IEEE 30-bus, IEEE 118-bus and IEEE 300-bus check system. The obtained results from the HMOAPO algorithm is compared with the other improvement techniques within the literature. The obtained comparison results indicate that proposed technique is effective to succeed in best resolution for the OPF drawback.
\end{abstract}

Copyright (c) 2019 Institute of Advanced Engineering and Science. All rights reserved.

\section{Corresponding Author:}

P. Nagalashmi,

Panacorp Software Solutions,

Nagercoil - 629001, India.

Email: nagaleshmip17@gmail.com

\section{INTRODUCTION}

Today's technological word fully depends on electricity; but the availability of electric source is low. The deficiency of electricity becomes the breaking point for emerging countries. Therefore, the research organizations tend into research to discover an appropriate solution for giving uninterruptable electricity. In this situation the usage of renewable energy sources are the superior solution, so these renewable energy systems are encouraged for electricity production [1], [2]. The most available renewable source in the world is wind and solar, the researches on these to area are under progressing but wind energy conversion is most promising research area because of its low complexity in installation and maintenance [3]. The wind energy systems are directly integrated into the power system for power system usage. The integration of wind energy into existing power system presents a technical problems and that needs attention of voltage regulation, stability, power quality issues [4].

The power quality is an important customer focused measure and is significantly affected by the operation of a distribution and transmission network. The issue of power quality is of great importance to the wind turbine [6]. By aggregating multiple wind turbines as wind farm or park, greater amount of electrical power can be generated from it. To interconnect wind power to the utility grid, there must be an appropriate grid interconnection, control system and regulation to ensure high power quality, reliability and stability. However, the one of the most critical problems associated with wind power is that, the amount of power generated by the same is affected by the intermittent nature of wind flow which is difficult to predict [7]. It 
follows that, the grid integrated wind powered units, may introduce severe challenges to traditional generation scheduling methodologies and operation of power system [8]. For satisfactory grid integration, the wind power fluctuation may have to be balanced by other types of generation. Alternatively, to compensate for the power imbalance due to uncertainty of wind, additional cost may have to be added with the total power generation cost of the system [9].

The major goal of Optimal Power Flow (OPF) is to improve a target capacity such as cost of fuel by means of ideal change of the control variables simultaneously different equality and inequality constraints. For the main intend of economical and secure operation and planning of power systems, optimal power flow (OPF) is employed [10]. The objective of OPF is to reduce the cost of fuel, environmental pollution and also the power lost by the network. In power system economic load dispatch (ELD) is commonly used to find generation or fuel cost. The major goal of Economic Dispatch (ED) is to minimize the amount of total pollution caused by the environment. This can be done by avoiding the burning of fuels [11]. Economic Load Dispatch (ELD) is determined as the technique in which the generation levels are allocated to the generating units. As a result the load of the system is totally and economically supplied. The ELD is a large-scale, highly non-linear, constrained optimization problem [12]. The main aim of ELD is conflicting in nature and to achieve an acceptable strategy of power dispatch within different system constraints and also it helps to keep the pollution within the limits and it reduces the fuel cost [13].

Application with renewable energy sources such as solar cell array, wind turbines, or fuel cells have increased significantly during the past decade. To obtain the clean energy, we are using the hybrid solar-wind power generation. Consumers prefer quality power from suppliers. The quality of power can be measured by using parameters such as voltage sag, harmonic and power factor. To obtain quality power we have different topologies. In our paper we present a new possible topology which improves power quality [14].

The hybrid power system is normally equipped with control system which functions to reduce the system frequency oscillations and makes the wind turbine generator power output follow the performance curve when the system is subjected to wind/load disturbances. Usually PI controllers are employed in these systems. Unfortunately since the operating point changes depending on the demand of consumers, this constant gain PI controller are unsuitable to other operating points. Therefore, it describes the application of fuzzy gain scheduling of PI controller for an isolated wind-diesel hybrid power system with superconducting magnetic energy storage [15].

Reduction of operating costs in power system in order to return the investment costs and more profitability has vital importance in power industry. Economic Load Dispatch (ELD) is one of the most important issues in reducing operating costs. ELD is formulated as a nonlinear optimization problem with continuous variables within the power plants. The main purpose of this problem is optimal planning of power generation in power plants with minimum cost by total units, regarded to equality and inequality constraints including load demand and the range of units' power productivity. In this article, Economic Load Dispatch problem has been modeled by considering the valve-point loading effects with power plants' constraints such as: the balance of production and consumption in system, the forbidden zones, range of production, increasing and decreasing rates, reliability constraints and network security [16].

In recent years wind turbine technology has undergone rapid developments, growth in size. The wind energy become increasingly competitive with conventional energy sources based on the optimization of wind turbines. The penetration of wind energy in the grid raises questions about the compatibility of the wind turbine power production with the grid. In particular, the contribution to grid stability, power quality and behavior during fault situations plays therefore as important a role as the reliability. In this paper, a vector control scheme is developed to control the rotor side voltage source converter [17].

A new control method for quasi-Z-source cascaded multilevel inverter-based grid-connected photovoltaic (PV) system is proposed. The proposed method is capable of boosting the PV array voltage to a higher level and solves the imbalance problem of DC-link voltage in traditional cascaded H-bridge inverters. This system adjusts the grid injected current in phase with the grid voltage and achieves independent maximum power point tracking (MPPT) for the separate PV arrays. To achieve these goals, the proportionalintegral (PI) controllers are employed for each module. For achieving the best performance, this paper presents an optimum approach to design the controller parameters using particle swarm optimization (PSO). The primary design goal is to obtain good response by minimizing the integral absolute error. Also, the transient response is guaranteed by minimizing the overshoot, settling time and rise time of the system response. The effectiveness of the new proposed control method has been verified through simulation studies based on a seven level quasi-Z-Source cascaded multilevel inverter [18].

Embellished Particle Swarm Optimization is to extend the single population PSO to the interacting multi-swarm model. Through this multi-swarm cooperative approach, diversity in the whole swarm community can be upheld. Concurrently, the swarm-to-swarm mechanism drastically speeds up the swarm community to converge to the global near optimum. In order to evaluate the performance of the proposed 
algorithm, it has been tested in standard IEEE 57,118 bus systems and results show that Embellished Particle Swarm Optimization (EPSO) is more efficient in reducing the Real power losses when compared to other standard reported algorithms [19].

The problem of Optimal Power Flow can be solved by utilizing various techniques like linear programming, non-linear programming, interior-point technique, quadratic programming, sequential unconstrained minimization and Newton based techniques and also it can be solved by the integration of optimization techniques like evolutionary programming (EP), particle swarm optimization (PSO), and sequential quadratic programming (SQP)[20]. There are two steps involved. In the first step, the solution space is investigated by both EP and PSO techniques. In the second step, SQP is utilized when there is a development in the result of first phase [21]. EP is a kind of global searching technique. It begins at the population of candidate solution and at last evaluation process is utilized to find the near global solution in parallel. GA is a search algorithm based on the mechanics of natural genetics and natural selection. The evolution procedure of organs with functional optimizations is integrated here. Reproduction, crossover and mutation are the three basic prime operators associated with GA. Based on the chromosomes, GA works. A set of binary digits which describes the control parameter coding is contained in these chromosomes which is composed themselves with genes [22], [23].

It is necessary to control the power flow at the optimal range while the renewable energy sources are used in power systems. The main contribution of this paper is i) To formulate the optimal power flow problem as a multi objective optimization problem ii) And to utilize the Artificial Physical Optimization (APO) algorithm with Animal migration optimization as a solution to the OPF problem. The remainder of this paper is organized as follows: Some of the recent related researches to our proposed method is explained in section 2. The proposed methodology with problem formulation is explained in section 3 . The Experimental results of the proposed method and the comparison with existing methods are presented in section 4 followed by the conclusion in section 5 .

\section{RELATED WORKS} as follows:

Some of the recent research work related to the OPF problem in wind energy system is listed

Shanhe Jiang et.al [24] introduced "A hybrid particle swarm optimization and gravitational search algorithm for solving economic emission load dispatch problems with various practical constraints". To solve economic emission load dispatch problem, in this paper PSO was integrated with GSA. Both the utilized approach was based on population. In PSO technique, the agents were taken as particle. Here the movement of each particle was based on both the past best solution of its own and the past best solution of its group. In GSA, the agents were taken as objects. Here the one object was fascinated by other objects through gravitational force. The agent in GSA was described through four types of parameters. The first parameter was the position of the mass in which solution to the problem was stated at specified search space. The second parameter was the inertial mass which decelerates its motion by reflection of its resistance. The third and fourth parameter was the active and passive gravitational mass. The estimation of both gravitational and inertial mass was done through fitness function. Both the algorithms were integrated by any one of the two procedures. (i.e.) one work starts after the completeness of the previous work and the other way was to employ co-evolutionary method to consider the swarm components as the components introduced by PSO-GSA.

Aniruddha Bhattacharya and Pranab Kumar Chattopadhyay [25] developed "Hybrid Differential Evolution with Biogeography-Based Optimization for Solution of Economic Load Dispatch". Here the issue of both convex and non-convex economic load dispatch was solved by the combination of differential evolution (DE) algorithm and biogeography-based optimization algorithm. The above combination of algorithms also solves problems like degradation of solution quality and low speed. The DE algorithm was based on population. Here functions like non-differentiable, nonlinear and multi-modal objective can be handled and a trial vector was constructed by each parent individual in order to produce new offspring. There were three types of basic operators was involved to enhance the population namely mutation, crossover, and selection. In Biogeography activities like the movement of one island to another, appearance and disappearance of new species were expressed. The quality of the solution will be degraded in later stage due to the existence of cross-over operation in evolutionary based algorithm whereas in BBO, cross-over operation was not restricted.

IejinCai et.al [26] presented "A hybrid CPSO-SQP method for economic dispatch considering the valve-point effects". In this paper, chaotic particle swarm optimization (CPSO) algorithm and sequential quadratic programming (SQP) were incorporated to retrieve the solution for economic power dispatch problem. Here the central optimizer was the CPSO and to enhance quality of the solution, the results were

Int J Pow Elec \& Dri Syst, Vol. 10, No. 1, March 2019 : 486-503 
adjusted by SQP. The CPSO was designed based on tent equation. CPSO was a combination of PSO and CLS. Where global exploration was carried out in PSO and local search was done to the solutions of the PSO through CLS. IN SQP, there were three stages. In the first stage, the Hessian matrix contained in the lagrangian function was updated. Estimation of line search and merit function was done at the second stage and finally solution was acquired for the problem of quadratic programming. The optimal power generation of each unit which was submitted to operation was found by the hybridization of CPSO-SQP technique.

Behnam Mohammadi-Ivatloo et.al [27] discussed "Nonconvex Dynamic Economic Power Dispatch Problems Solution Using Hybrid Immune-Genetic Algorithm". The cost needed for operation was reduced and also the solution for the problem of dynamic economic dispatch (DED) in a non-convex solution space was found by the consolidation of immune algorithm (IA) and genetic algorithm (GA). In IA, when the extraneous molecules was arrived in the immune system of human body a reaction occurs. Even though this algorithm does not contain any knowledge about that molecule, they were analyzed by this algorithm after some time and also solution for the removal of these molecules was found. Here the extraneous molecule was known as antigens and the reaction of the immune system was known as antibodies. The antibodies should be balanced with the unknown antigens. The antibodies were given by the objective function, its combined constraints from the antigens and the solutions which enhance them. Some antibodies was generated by the human body at the initial stage and those antibodies was compared with the newcomer antigens and the identical properties between them was estimated. This estimation was known as affinity factor.

K. Vaisakh et.al [28] designed "Solving dynamic economic dispatch drawback with security constraints exploitation bacterial forage PSO-DE algorithm". Here problems like non-smooth, non-convex nature attributable to valve-point loading effects, ramp rate limits, spinning reserve capability, prohibited in operation zones and security constraints was shown in DED drawback. The on top of mentioned issues is often defeated by the mixing of bacterial forage Particle Swarm improvement (BPSO) with differential evolution (DE) algorithmic rule. The BPSO was a mixture of microorganism forage optimization algorithmic rule and PSO. The bacterium with positive foraging methods was chosen by the PSO operator within the change method of each chemo-tactic step, so as to get reduced price. In our new BPSO-DE approach, the primary step was the substitution of velocity in place of delta. Within the second step, through the calculation of fitness operate the population of best fitness within the current generation and also the worth for world best fitness was obtained. Within the third step, the position of generation was modified to a replacement position. Within the fourth step, to retrieve the losses from power, apparent power within the lines and voltages of load was retrieved by the load flow operation that was done with those new populations made at the previous step. Within the fifth step the violations was verified for the line flows and cargo voltages. If it contains violations then penalty terms were additional to the fitness operate of each BPSO and Delaware. Each the fitness functions were compared for each bacterial population and also the best worth was keeping in an exceedingly separate variable. The simplest value of fitness, real power generation price, voltages, line flows, power losses for the given interval were updated for all the microorganism population as pbest and global best (gbest). Then the procedure for next chemo-tactic step was continual.

\section{PROPOSED OPTIMIZATION SOLUTION TO OPF PROBLEM}

In a wind energy system, Optimal Power Flow (OPF) is a Multi-objective optimization problem that seeks to find out a compromise solution to minimize the fuel cost, power loss, emission and maintaining voltage stability. The Solution of optimal power flow (OPF) problem aims to optimize a selected objective function through optimal adjustment of the power system control variables while at the same time satisfying the various equality and inequality constraints. According to the results of previous investigations, Animal Migration Optimization (AMO) and Artificial Physical Optimization (APO) have better performance for solving optimizations problems. In this work, we intend to propose a Hybrid Multi objective Artificial Physical Optimization (HMOAPO) is to solving the OPF (Optimal Power Flow) problem in wind energy system. The architecture of our proposed work is shown in Figure 1. 


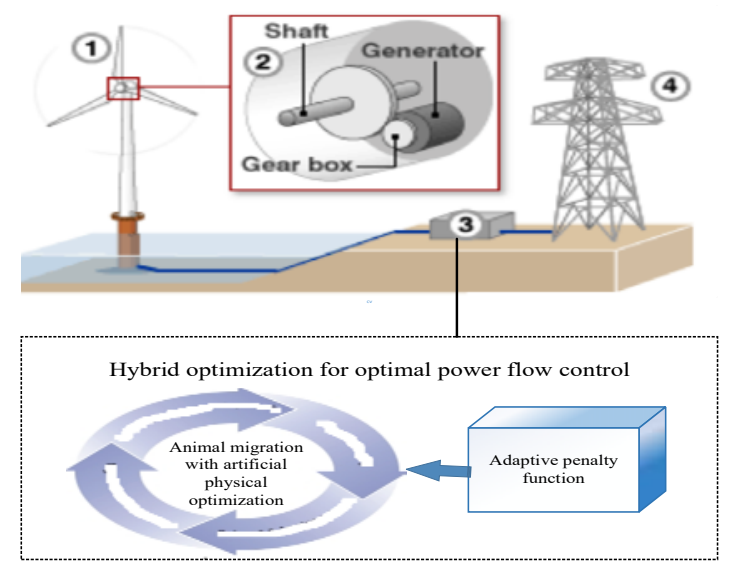

Figure 1. Architecture of our proposed work

To enhance the performance of APO, this work applies an Animal Migration algorithm (AMO) which follows three main rules for each individual and also to overcome the drawback of premature convergence. In addition, the MOAPO is combined with Adaptive Penalty Function to handle equality and inequality constrains associated with OPF problems. The adaptive penalty function (APF), which convert a constrained problem into an unconstrained one where the 'Penalty Function' penalize the infeasible solutions to move towards desirable feasible solutions.

\subsection{OPF problem definition}

The OPF problem is considered as a general optimization problem. The OPF problem expects to reduce the whole fuel cost perform whereas fulfilling the whole load, completely different equality and difference constraints. Likewise, the best values of the management variables within the power grid are resolved within the OPF problem. Mathematical expression belonging to the matter is delineating as follows.

$$
\operatorname{Min}\left(\mathrm{OF}_{1}, \mathrm{OF}_{2}, \mathrm{OF}_{3}, \mathrm{OF}_{4}, \mathrm{OF}_{5}, \mathrm{OF}_{6}\right)^{\mathrm{T}}
$$

Subject to:

$$
\begin{aligned}
& P_{G i}-P_{D i}=\left|V_{i}\right| \sum_{j=1}^{N}\left|V_{j}\right|\left(G_{i j} \cos \delta_{i j}+B_{i j} \sin \delta_{i j}\right), \forall i \in N, \\
& Q_{G i}+Q_{C i}-Q_{D i}=\left|V_{i}\right| \sum_{j=1}^{N}\left|V_{j}\right|\left(G_{i j} \sin \delta_{i j}-B_{i j} \cos \delta_{i j}\right), \forall_{i} \in N, \\
& P_{G i}^{\min } \leq P_{G i} \leq P_{G i}^{\max }, \forall i \in N_{g}, \\
& Q_{G i}^{\min } \leq Q_{G i} \leq Q_{G i}^{\max }, \forall i \in N_{g}, \\
& \left|V_{i}^{\min }\right| \leq\left|V_{i}\right| \leq\left|V_{i}^{\max }\right|, \forall i \in N, \\
& t_{k}^{\min } \leq t_{k} \leq t_{k}^{\max }, \forall k \in N_{t}, \\
& S_{l i} \leq S_{l i}^{\text {rated }}, \forall i \in n b r, \\
& Q_{c i}^{\min } \leq Q_{c i} \leq Q_{c i}^{\max }, \forall i \in N_{c}, \\
& L S I_{i j}=\frac{4 X_{i j} Q_{j}}{\left.\left|V V_{i}\right| \sin \left(\theta+\delta_{i}-\delta_{j}\right)\right]^{2} \leq 1}
\end{aligned}
$$




$$
\begin{aligned}
& \theta=\tan ^{-1}\left(\frac{X_{i j}}{R_{i j}}\right), \\
& Q_{j}=\frac{\left|V_{i}\right|\left|V_{j}\right|}{\left|Z_{i j}\right|} \sin \left(\theta+\delta_{i}-\delta_{j}\right)-\frac{\left|V_{j}\right|^{2}}{\left|Z_{i j}\right|} \sin \theta .
\end{aligned}
$$

In this work, the target perform of the OPF problem is proposed because the total generation value as well as valve-point impact, loss minimization and prohibited zones. The power flow equations are thought-about because the equality constraints. The transmission limits and alternative security limits are used as difference constraints. The vectors are outlined as state variable and control variable vectors are outlined as follows:

$$
\left[P_{g-1} \ldots \ldots . P_{g-N g}, V_{g-1} \ldots \ldots . V_{g-N g}, T_{1} \ldots \ldots \ldots T_{N \mathrm{~N}}, Q_{c-1} \ldots \ldots . . Q_{c-N c}\right]
$$

Where $P_{g}, V_{g}, T_{N t}, Q_{c}$ are described as the active power of the slack bus, the voltage magnitude of the load buses, active power output of the generators except at the slack bus, the reactive power of the generators respectively.

$$
\left\lfloor Q_{g-1} \ldots . . Q_{g-N g}, V_{P Q-1} \ldots \ldots . V_{P Q-N_{P Q}}, S_{l_{1}} \ldots \ldots . S_{l_{\text {nor }}}\right\rfloor .
$$

Where $Q_{g}, V_{P Q}$ and $S_{l}$ are defined as the reactive power generation at bus, the voltage of load bus and the line flow, respectively.

Objective function

In this paper, the objective function of the OPF problem is defined as minimization of the total fuel cost of the power generation system. The total fuel cost can be mathematically defined as follows:

$$
O F_{1}=\sum_{i=1}^{N g}\left(a_{i} P_{G i}^{2}+b_{i} P_{G i}+c_{i}\right)
$$

Where $P G_{i}$ are represented as the active power output of the $i^{\text {th }}$ generator, respectively. $a_{i}, b_{i}$ and $C_{i}$ are the fuel cost coefficients of the $i^{\text {th }}$ generator.

\subsection{The generation cost minimization with valve point loading (VPL) effect}

The generation cost with valve-point effect is presented as follows:

$$
O F_{2}=\sum_{i=1}^{N g}\left(a_{i} P_{G i}^{2}+b_{i} P_{G i}+c_{i}\right)+\left|d_{i} \times \sin \left(e_{i} \times\left(P_{G i}^{\min }-P_{G i}\right)\right)\right|
$$

Where $d_{i}$ and $e_{i}$ are coefficients of the valve-point effect of the $i^{\text {th }}$ generator. Typical curve related to fuel cost with and without valve-point effect of the generation units is shown in Figure2.

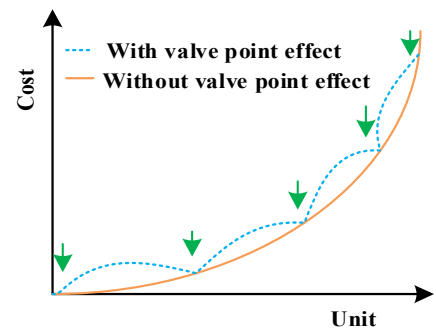

Figure 2. Typical curve related to fuel cost with and without valve-point effect of the generation units 
Let $W_{j, k}\left(P_{w j, k}\right)$ be the electrical energy cost of wind power of the $j^{\text {th }}$ wind farm and the $k^{\text {th }}$ wind power generator. Therefore, the cost of the wind unit can be defined by:

$$
W_{j, k}\left(P_{w j, k}\right)=\psi_{j, k} \widehat{P}_{j, k}+\psi_{z_{1}, j, k} \times\left(\widetilde{P}_{j, k}-\hat{P}_{j, k}\right)+\psi_{z_{2}, j, k}\left(\widetilde{P}_{j, k}-\widehat{P}_{j, k}\right)
$$

Which, $\widehat{P}_{j, k}, \widetilde{P}_{j, k}$ are expected and available generation output of the unit $\mathrm{j}$ in the wind farm k (MW). $\psi_{j, k}, \quad \psi_{z_{1}, j, k}$ and $\psi_{z_{2}, j, k}$ are namely direct, overestimation and underestimation electrical wind energy cost coefficient of the unit $j$ in the wind farm $k(\$ / M W h)$.

\subsection{Generating units with prohibited operating zones (POZs)}

The physical limitations of the power plant components, prohibited operating zones (POZs) are occurred in a hydro-generating unit. This constraint dictates several feasible sub-regions for hydro-generating units as shown in Figure 3 and can be expressed by:

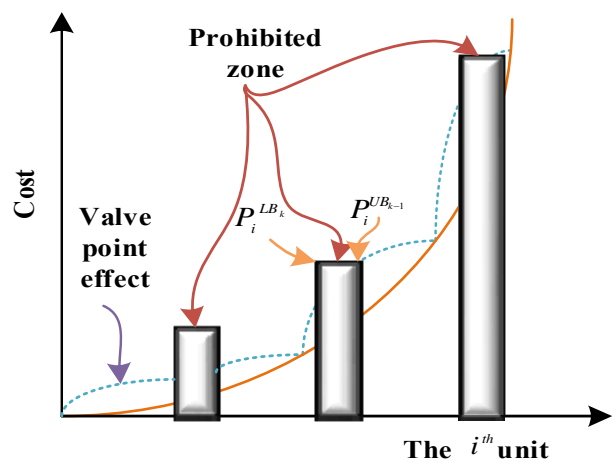

Figure 3. Topology of cost function with prohibit zone constraint and valve point effect

$$
\left\{\begin{array}{l}
P_{i}^{\min } \leq P_{i} \leq P_{i}^{L B_{i}} \\
\vdots \\
P_{i B_{B_{1}-1}}^{L P_{i}} \leq P_{i} \leq P_{i}^{L B_{i}}, i=1,2, \ldots \ldots, N_{g}, k=1,2, \ldots \ldots, N_{k} \\
P_{i}^{U B_{i}} \leq P_{i} \leq P_{i}^{\max }
\end{array}\right.
$$

Which, $P_{i}^{U B_{k-1}}$ and $P_{i}^{L B_{k}}$ are upper and lower limits of the $k^{\text {th }}$ sub-regions of the $i^{\text {th }}$ unit, respectively. $N_{g}$ and $N_{k}$ are the number of thermal units and sub-regions.

Power Loss Minimization

The total real power loss in power systems is represented by

$$
O F_{3}=\sum_{i=1}^{N} \sum_{j=1}^{N}\left[\alpha_{i j}\left(P_{i} P_{j}+Q_{i} Q_{j}\right)+\beta_{i j}\left(Q_{i} P_{j}+P_{i} Q_{j}\right)\right]
$$

Which ${ }_{\alpha_{i j}}=\frac{r_{i j}}{V_{i} V_{j}} \cos \left(\delta_{i}-\delta_{j}\right), \beta_{i j}=\frac{r_{i j}}{V_{i} V_{j}} \sin \left(\delta_{i}-\delta_{j}\right), V_{i} \prec \delta_{i}$ is the complex voltage at the bus $i^{\text {th }} \cdot Z_{i j}=r_{i j}+j x_{i j}$ is the $i^{\text {th }}$ element of [Zbus] impedance matrix. $P_{i}$ and $P_{j}$ are the active power injections at the $i^{\text {th }}$ and $j^{\text {th }}$ buses, respectively. $Q_{i}$ and $Q_{j}$ are the reactive power injections at the $i^{\text {th }}$ and $j^{\text {th }}$ buses, respectively. $N$ is the number of buses.

L-index minimization

The voltage stability index (VSI) which ensures secure operations and is written as follows 


$$
\begin{aligned}
& O F_{4}=\sum_{i=1}^{N}\left(\frac{\left|V_{i}\right|-V_{\text {avg }}}{d V}\right), V_{\text {avg }}=\left(\frac{\left|V_{\max }\right|-\left|V_{\min }\right|}{2}\right) \text { and } \\
& d V=\left(\frac{\left|V_{\max }\right|-\left|V_{\min }\right|}{2}\right)
\end{aligned}
$$
as follows:

Where $n$ is selected to be equal 1.Finally, wind power can be expressed by the piecewise linear

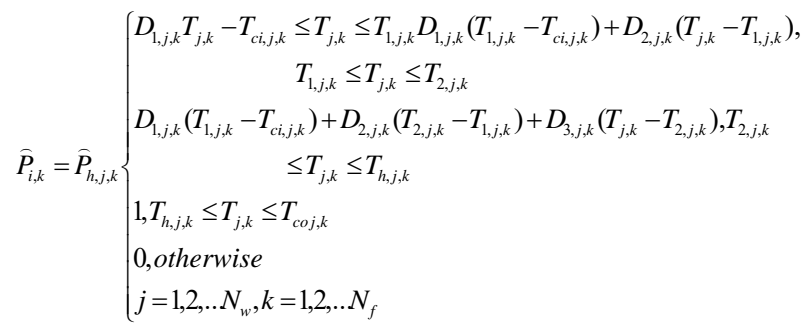

Which, Di,j,k is slope of section $j$ of the wind unit $w$ in wind farm $f(\mathrm{MWs} / \mathrm{m}) . T c i, j, k, T c o, j, k, T i, j, k$ and $T h, j, k$ are cut-in wind speed, cut-out wind speed, breakpoint of segment $i$ and rated wind speed, for all the wind units $w$ in the wind farm $(\mathrm{m} / \mathrm{s})$, respectively.

\section{Artificial Physical Optimization}

APO is a nature-inspired metaheuristic method inspired by natural physical forces based on artificial physics (AP) framework [29]which is developed by Spear et al. Based on the similarity among the AP method and population-based optimization algorithm, recently some authors proposed APO and tested its optimization performance [30-32]. APO can be described briefly as follows

Assume the optimization problem can be expressed as

$$
\begin{aligned}
& \min f\left(x^{d}\right) \\
& \text { s.t. } \quad x_{d}^{\min } \leq x^{d} \leq x_{d}^{\max }, \quad d=1,2, \ldots \ldots . ., D
\end{aligned}
$$

Where $D$ is the dimension of the problem, $x_{\min }^{d}$ and $x_{\max }^{d}$ are the minimum and maximum limits of variable $x^{d}$.

The particle's position signifies the solution to the optimization problem. The position of particle $i$ is defined as

$$
X_{i}=\left[x_{i}^{1}, x_{i}^{2}, \ldots \ldots ., x_{i}^{d}, \ldots \ldots, x_{i}^{D}\right] \quad i=1,2, \ldots \ldots \ldots . . N P .
$$

Where NP is the number of individuals in APO; $x_{i}^{d}$ is the position of the $i^{\text {th }}$ individual in $d^{\text {th }}$ dimension.

Step 1: Population Initialization.

The NP individual's positions are randomly formed in the n-dimensional decision space.

The NP individual's velocities are set to be zero.

Step 2: Fitness calculation.

Compute the fitness of each individual according to the objective function.

Step 3: Force calculation.

In the APO, the process of optimization is continuously performed by moving the individual toward the promising region until the optimal solutions is found. And the rules for moving the individuals are decided by the forces act on each other. The rules can be expressed by the following equations:

\section{SIMULATION RESULTS AND COMPARISONS}

The proposed algorithm is developed using MATLAB version 6.5 programming language and the proposed methodology is tested in IEEE 30-bus system and the samples are tested on 2.6-Ghz Pentium-IV PC. The generators data and cost coefficients are gathered from [25].

Solution for optimal power flow problem in wind energy system using hybrid... (P. Nagaleshmi) 


\subsection{Case studies on the IEEE 30-bus System}

4.1.1. Comparison with global optimization

Initially the sample is tested in IEEE 30-bus, 41-branch system with the voltage constraint of lower and upper limits are 0.9 p.u and 1.1 p.u., respectively. The APO population size is taken equal 30 , the most range of generation is 100 , and crossover and mutation are applied with initial likelihood zero.9 and 0.01 severally. Figure 4 shows the topology of normal IEEE 30 bus system.

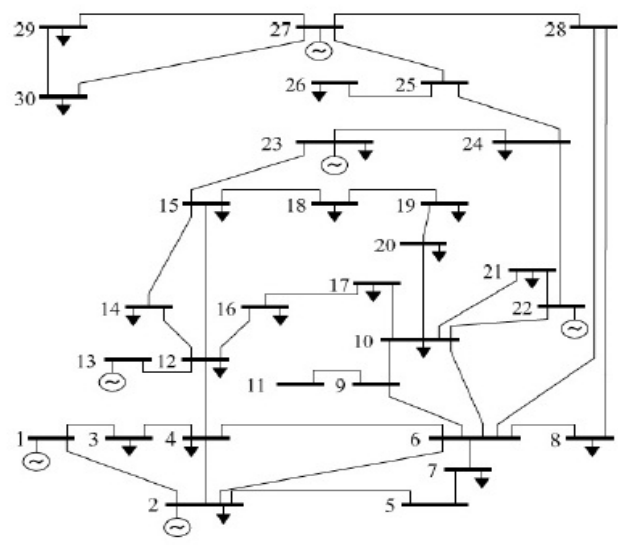

Figure 4. IEEE 30 bus system

For the aim of supportive the efficiency of the proposed approach, we have a tendency to created a comparison of our efficiency with others competitive OPF efficiency. In [25], they conferred a typical GA, in [3] the authors conferred associate enhanced GA, and so in [26], they proposed an Improved evolutionary programming (IEP). In [27] they presented an optimum power flow solution using GA-Fuzzy system approach (FGA), and in [11] a changed differential evolution is proposed (MDE). The budget items in our proposed approach is 800.8336 and therefore the power loss is 8.92 that area unit higher than the others strategies reported within the literature. Result in Table 1 show clearly that the proposed approach provides higher results.

Table 1. Results of the minimum cost and power generation compared with:

SGA, EGA, IEP, FGA and MDE for IEEE 30-bus

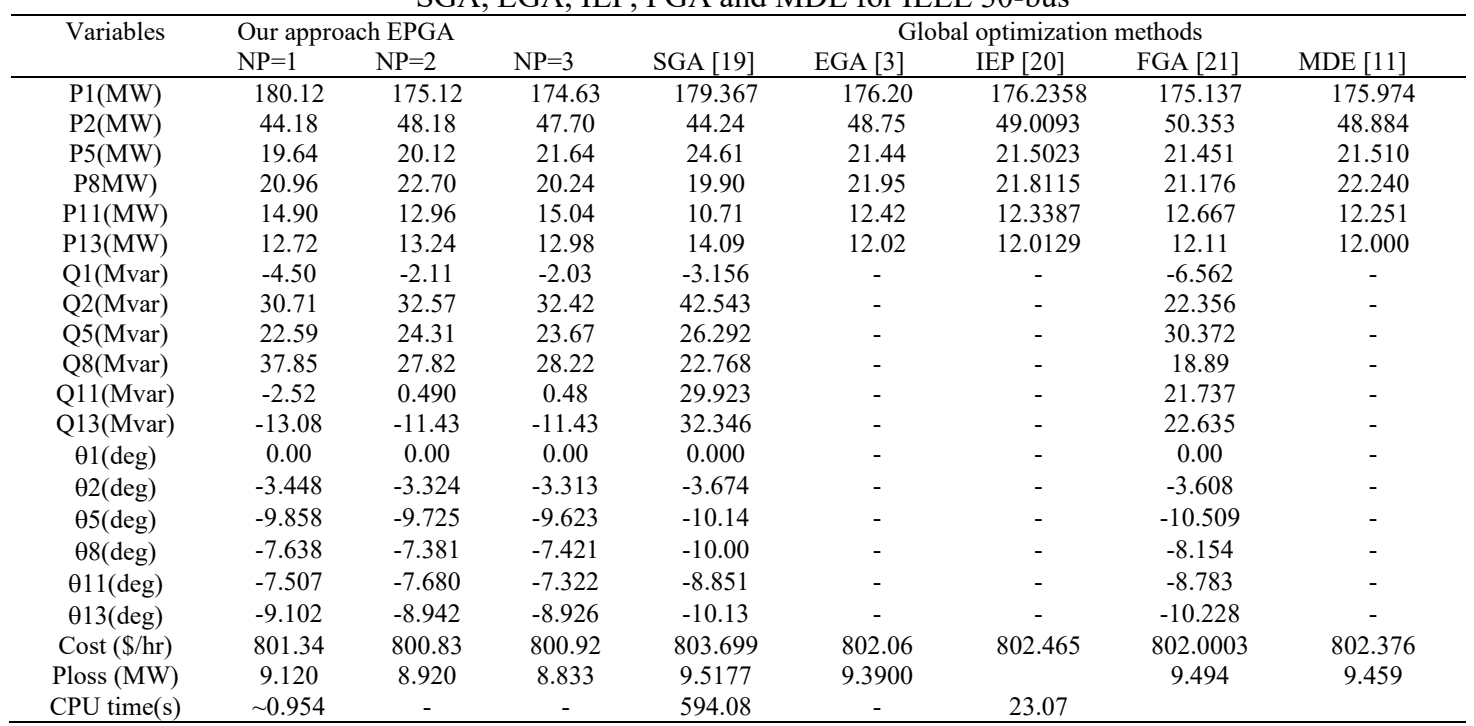

Int J Pow Elec \& Dri Syst, Vol. 10, No. 1, March 2019 : 486 - 503 
Table 1 denotes the cost consumption of the proposed and prevailing global methodologies.It is clearly seen that the cost consumption of the prevailing methodologies such as $\mathrm{S}_{\mathrm{ga}}, \operatorname{tga}, \mathrm{I}_{\mathrm{ep}}, \mathrm{F}_{\mathrm{ga}}$ and $\mathrm{M}_{\mathrm{de}}$ are comparatively higher than that of the cost consumption of our proposed methodology implying EPGA.This clearly depicts the cost efficiency of our framework from others.

Table 2 shows the best solution of shunt compensation obtained at the standard load demand $(\mathrm{Pd}=283.4 \mathrm{MW})$ using reactive power planning. This describes the shunt reactive power compensation of Epga and Ega where comparatively betterment is shown in favour of Epga. The transmission line loading after optimization compared to aco and fga for ieee 30-bus as shown in Table 3.

Table 2. Comparative results of the shunt reactive power compensation between

\begin{tabular}{ccccccccc}
\multicolumn{10}{c}{ EPGA and EGA [7] for ieee 30-bus } \\
\hline Shunt $N^{\circ}$ & 1 & 2 & 3 & 4 & 6 & 7 & 8 & 9 \\
\hline Bus N $^{\circ}$ & 10 & 12 & 15 & 17 & 21 & 23 & 24 & 29 \\
Best Qsvc [pu] & 0.1517 & 0.0781 & 0.029 & 0.0485 & 0.0602 & 0.0376 & 0.0448 & 0.0245 \\
Best case bsh [pu] [7] & 0.05 & 0.05 & 0.03 & 0.05 & 0.05 & 0.04 & 0.05 & 0.03 \\
\hline
\end{tabular}

Table 3. Transmission line loading after optimization compared to ACO and FGA for ieee 30-bus

\begin{tabular}{|c|c|c|c|c|c|}
\hline \multirow{3}{*}{ Line } & \multirow{3}{*}{$\begin{array}{l}\text { Rating } \\
\text { (MVA) }\end{array}$} & \multicolumn{2}{|c|}{ EPGA: $\mathrm{PD}=283.4 \mathrm{MW}$} & \multirow{3}{*}{$\begin{array}{c}\text { ACO [22] } \\
\text { To Bus } \\
\text { P(MW) }\end{array}$} & \multirow{3}{*}{$\begin{array}{c}\text { FGA [21] } \\
\text { To Bus } \\
+(\mathrm{P}(\mathrm{MW}))\end{array}$} \\
\hline & & From Bus & To Bus & & \\
\hline & & $\mathrm{P}(\mathrm{MW})$ & $\mathrm{P}(\mathrm{MW})$ & & \\
\hline $1-2$ & 130 & 113.9200 & -7.7300 & -119.5488 & 117.211 \\
\hline $1-3$ & 130 & 60.7100 & 5.7000 & -58.3682 & 58.3995 \\
\hline $2-4$ & 65 & 32.0600 & 4.3000 & -34.2334 & 34.0758 \\
\hline $3-4$ & 130 & 56.8600 & 3.7900 & -55.5742 & 54.5622 \\
\hline $2-5$ & 130 & 62.4200 & 4.9000 & -62.4522 & 63.7783 \\
\hline $2-6$ & 65 & 43.3000 & 2.4400 & -44.5805 & 45.3399 \\
\hline $4-6$ & 90 & 49.1700 & -8.0100 & -49.0123 & 50.2703 \\
\hline $5-7$ & 70 & -11.7900 & 7.2300 & 11.2939 & 14.1355 \\
\hline $6-7$ & 130 & 34.9800 & 0.8800 & -34.0939 & 33.9924 \\
\hline $6-8$ & 32 & 11.8500 & -1.3200 & -11.0638 & 13.6882 \\
\hline $6-9$ & 65 & 16.5700 & -3.3400 & -19.7631 & 22.4033 \\
\hline $6-10$ & 32 & 12.5400 & 0.0700 & -13.1277 & 14.6187 \\
\hline $9-11$ & 65 & -15.0400 & -0.0700 & 10.4330 & 24.1764 \\
\hline $9-10$ & 65 & 31.6100 & -3.8000 & -30.1961 & 32.7929 \\
\hline $4-12$ & 65 & 31.2200 & 16.7200 & -33.1670 & 30.5889 \\
\hline $12-13$ & 65 & -12.9800 & 11.8000 & 12.1730 & 24.9376 \\
\hline $12-14$ & 32 & 7.6600 & 1.0500 & -8.0453 & 7.6911 \\
\hline $12-15$ & 32 & 18.1000 & 1.4900 & -18.1566 & 17.4525 \\
\hline $12-16$ & 32 & 7.2400 & 1.3600 & -7.4961 & 6.34027 \\
\hline $14-15$ & 16 & 1.4000 & -0.6800 & -1.8340 & 1.2313 \\
\hline $16-17$ & 16 & 3.6900 & -0.5400 & -3.9715 & 3.2983 \\
\hline $15-18$ & 16 & 5.8900 & 1.9700 & -6.2224 & 5.4066 \\
\hline $18-19$ & 16 & 2.6500 & 1.0000 & -3.0140 & 2.3627 \\
\hline $19-20$ & 32 & -6.8500 & -2.4100 & 6.5015 & 8.5117 \\
\hline $10-20$ & 32 & 9.1500 & 3.3200 & -8.7015 & 11.0315 \\
\hline $10-17$ & 32 & 5.3200 & 0.8600 & -5.0285 & 9.861616 \\
\hline $10-21$ & 32 & 16.1000 & 3.9800 & -15.8419 & 18.96153 \\
\hline $10-22$ & 32 & 7.7800 & 1.7400 & -7.6778 & 9.0741 \\
\hline $21-22$ & 32 & -1.4800 & -0.6100 & 1.6585 & 2.0887 \\
\hline $15-23$ & 16 & 5.2100 & -0.7000 & -5.4613 & 4.5343 \\
\hline $22-24$ & 16 & 6.2600 & 1.0400 & -5.9593 & 6.9397 \\
\hline $23-24$ & 16 & 1.9900 & 1.8800 & -2.2388 & 1.14447 \\
\hline $24-25$ & 16 & -0.5000 & 1.1200 & 0.5027 & 1.3934 \\
\hline $25-26$ & 16 & 3.5400 & 2.3600 & -3.5000 & 4.2647 \\
\hline $25-27$ & 16 & -4.0500 & -1.2400 & 4.0748 & 5.633 \\
\hline $27-28$ & 65 & 17.3200 & 2.9500 & -17.3814 & 19.7428 \\
\hline $27-29$ & 16 & 6.1900 & -0.2900 & -6.1070 & 6.4154 \\
\hline $27-30$ & 16 & 7.0600 & 0.8900 & -6.9295 & 7.2897 \\
\hline $29-30$ & 16 & 3.7200 & 1.3500 & -3.6705 & 3.7542 \\
\hline $8-28$ & 32 & 2.0700 & -2.1900 & -2.2067 & 3.3685 \\
\hline $6-28$ & 32 & 15.2900 & -0.6800 & -15.1747 & 16.5409 \\
\hline Ploss (MW) & & & & 9.8520 & 9.494 \\
\hline
\end{tabular}


The operation costs of the most effective solutions for the new system composed by 2 partitions and for the new system composed by 3 partitions area unit $800.8336 \$ / \mathrm{h}$ and 800.9265 , severally , $(0.0929$ difference). The variations between the values are not important compared to the initial network while not partitioning. This proves that the new subsystems generated conserve the physical proprieties and performances of the initial network. Table three shows that the road flows obtained area unit well underneath security limits compared to FGA algorithm and ACO algorithm [28].

\subsubsection{Comparison with PSAT and MATPOWER OPF solver}

For the purpose of verifying the robustness of the proposed algorithm we made a second comparison with PSAT and MATPOWER packages under severe loading conditions. In this work the increase in the load is regarded as a parameter which affects the power system to voltage collapse.

$$
\left\{\begin{array}{l}
P_{L}=\text { Kld } . P_{o L} \\
Q_{L}=K l d . Q_{o L}
\end{array}\right.
$$

Where, $P_{o L}$ and $Q_{o L}$ are the active and reactive base loads, $P_{L}$ and $Q_{L}$ are the active and reactive loads at bus $\mathrm{L}$ for the current operating point. Kld Represents the loading factor.

Table 4. Results of the minimum cost and power generation compared with: PSAT and MATPOWER package for ieee 30-bus

\begin{tabular}{|c|c|c|c|c|c|c|}
\hline \multirow[t]{2}{*}{ Variables } & \multicolumn{2}{|c|}{ Our Approach EPGA } & \multicolumn{2}{|c|}{ MATPOWER } & \multicolumn{2}{|c|}{ PSAT } \\
\hline & $\mathrm{Kld}=18 \%$ & $\mathrm{Kld}=32 \%$ & $\mathrm{Kld}=18 \%$ & $\mathrm{Kld}=32 \%$ & $\mathrm{Kld}=18 \%$ & $\mathrm{Kld}=32 \%$ \\
\hline P1(MW) & 192.66 & 199.30 & 200.00 & 200.0 & 200.00 & 200.0 \\
\hline P2(MW) & 58.94 & 70.60 & 55.00 & 69.74 & 54.9925 & 69.9368 \\
\hline P5(MW) & 23.22 & 29.08 & 23.70 & 28.40 & 23.6957 & 28.5135 \\
\hline P8(MW) & 33.98 & 33.66 & 35.00 & 35.00 & 35.00 & 35.00 \\
\hline P11(MW) & 16.60 & 29.32 & 17.01 & 28.03 & 17.0154 & 28.2596 \\
\hline P13(MW) & 20.40 & 25.10 & 15.84 & 26.47 & 15.8827 & 26.7635 \\
\hline Q1(Mvar) & -5.26 & -6.18 & -13.94 & -17.66 & -15.6226 & -9.4127 \\
\hline Q2(Mvar) & 38.07 & 40.02 & 37.18 & 43.69 & 38.5416 & 60.4752 \\
\hline Q5(Mvar) & 35.25 & 42.28 & 36.10 & 42.62 & 36.5254 & 49.5412 \\
\hline Q8(Mvar) & 35.95 & 43.54 & 47.96 & 60.00 & 49.525 & 50.00 \\
\hline Q11(Mvar) & 1.150 & 2.06 & 3.680 & 6.910 & 4.6425 & 21.1631 \\
\hline Q13(Mvar) & -11.73 & -11.04 & -11.68 & -2.270 & 2.3642 & 19.7389 \\
\hline$\theta 1(\operatorname{deg})$ & 0.00 & 0.00 & 0.00 & 0.00 & 0.00 & 0.00 \\
\hline$\theta 2(\mathrm{deg})$ & -3.684 & -3.972 & -4.028 & -4.022 & -4.0412 & -4.026 \\
\hline$\theta 5(\mathrm{deg})$ & -11.218 & -12.002 & -11.841 & -12.518 & -11.8475 & -12.6009 \\
\hline$\theta 8(\mathrm{deg})$ & -8.055 & -8.588 & -8.737 & -9.065 & -8.7607 & -8.7792 \\
\hline$\theta 11$ (deg) & -11.995 & -6.847 & 8.931 & -7.386 & -8.9022 & -7.0128 \\
\hline$\theta 13$ (deg) & -9.344 & -9.423 & -10.642 & -9.751 & -10.6419 & -9.8547 \\
\hline Cost $(\$ / \mathrm{hr})$ & 993.6802 & 1159.6 & 993.98 & 1160.56 & 994.1047 & 1164.1706 \\
\hline Ploss MW & 11.390 & 12.975 & 12.141 & 13.556 & 12.174 & 14.385 \\
\hline
\end{tabular}

The results together with the generation cost, the ability losses, reactive power generation, and also the angles are shown in Table 4 . We can clearly observe that the whole cost of generation and power losses are higher than the results obtained by PSAT and MATPOWER at each loading issue (kld $=18 \%$ and $\mathrm{kld}=32 \%)$. as an example, at loading issue $32 \mathrm{nd}(\mathrm{PD}=374.088)$ the distinction in generation cost between our approach and to the 2 Packages (1159.6 \$/h compared to $1160.56 \$ / \mathrm{h}$ and $1164.1706 \$ / \mathrm{h}$ ) and in real power loss (12.975 MW compared to thirteen.556 MW and 14.385 MW) obtained from MATPOWER and PSAT severally.

Table 5 depicts the results of minimum cost, power generation, power losses, reactive power generation, and angles. At loading issue kld $=48.5 \%$, the two simulation Package (PSAT and MATPOWER) did not converge. A wider comparison is done with the PSAT and MATPOWER in order to verify the robustness of this framework. Similarly, the cost factor also analyzed for betterment with both methods. The approach proposed provides acceptable answer, the minimum total cost is $1403.5 \$ / \mathrm{h}$.

Voltage profile at loading factor: $\mathrm{kld}=48.5 \%$ as shown in Figure 5 . Lines power flow at critical loading factor kld $=48.5 \%$ as shown in Figure 6 . Reactive power exchanged between SVC controllers and the network at loading factor: kld $=48.5 \%$ as shown ini Figure 7.

Int J Pow Elec \& Dri Syst, Vol. 10, No. 1, March 2019: 486 - 503 
Table 5. Results of the minimum cost and power generation compared with PSAT And MATPOWER package for ieee 30-bus

\begin{tabular}{|c|c|c|c|}
\hline \multirow[t]{2}{*}{ Variables } & \multicolumn{3}{|c|}{$\begin{array}{c}\text { Loading Factor Kld }=48.5 \% \\
P D=420.85 \mathrm{MW}\end{array}$} \\
\hline & Our Approach & PSAT & MATPOWER \\
\hline P1(MW) & 199.98 & & \\
\hline P2(MW) & 79.96 & & \\
\hline P5(MW) & 49.98 & & \\
\hline P8(MW) & 34.92 & & \\
\hline P11(MW) & 30.00 & & \\
\hline P13(MW) & 39.90 & & \\
\hline Q1(Mvar) & -5.680 & & \\
\hline Q2(Mvar) & 41.62 & & \\
\hline Q5(Mvar) & 45.14 & & \\
\hline Q8(Mvar) & 53.31 & Did not Converge & Did not Converge \\
\hline Q11(Mvar) & 2.910 & & \\
\hline Q13(Mvar) & -10.33 & & \\
\hline$\theta 1(\mathrm{deg})$ & 0.000 & & \\
\hline$\theta 2(\mathrm{deg})$ & -3.761 & & \\
\hline$\theta 5(\mathrm{deg})$ & -11.907 & & \\
\hline$\theta 8(\mathrm{deg})$ & -8.972 & & \\
\hline$\theta 11(\mathrm{deg})$ & -7.228 & & \\
\hline$\theta 13(\mathrm{deg})$ & -8.237 & & \\
\hline Cost (\$/hr) & 1403.5 & & \\
\hline Ploss (MW) & 13.8960 & & \\
\hline
\end{tabular}

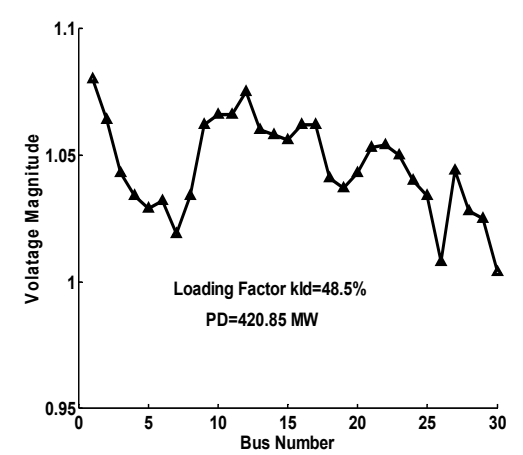

Figure 5. Voltage profile at loading factor: $\mathrm{kld}=48.5 \%$

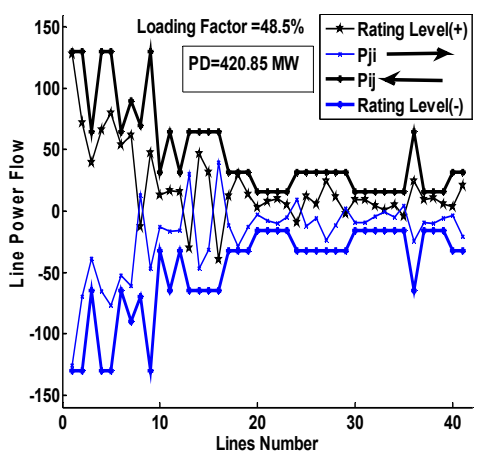

Figure 6. Lines power flow at critical loading factor $\mathrm{kld}=48.5 \%$

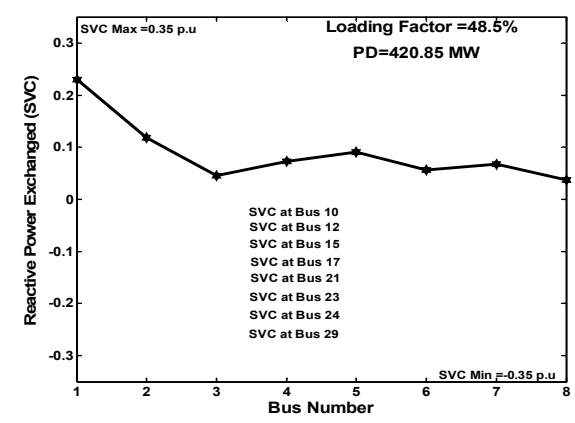

Figure 7. Reactive power exchanged between SVC controllers and the network at loading factor: $\mathrm{kld}=48.5 \%$ 

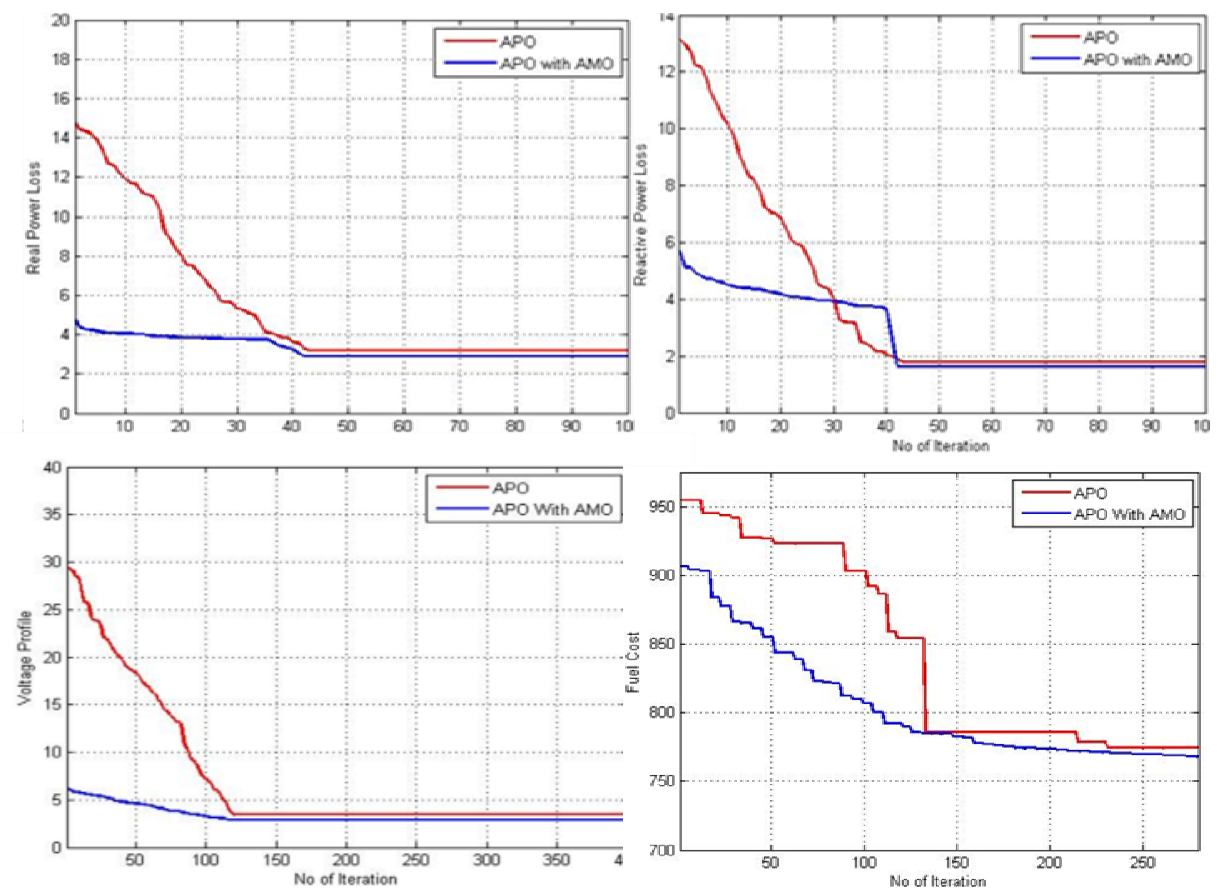

Figure 8. Convergence of IEEE 30 bus system

The protection constraints are checked for voltage magnitudes, angles and branch flows. The protection constraints are checked for voltage magnitudes, angles and branch flows. Figure 5 shows that the voltages magnitudes are within the desired security limits. Fig. 6 shows clearly that the transmission lines loading do not exceed their higher limits. Figure 7 shows the reactive power changed between SVC Controllers installed in at a specified buses and also the network.

The convergence values of IEEE 30 bus system on multi objective basis is shown in above Figure 8 . The variation with real power loss, reactive power loss, voltage profile and fuel cost for the standard IEEE 30 bus system with combined APO with AMO and APO is presented and it shows the importance of utilizing APO with AMO than APO.

\subsection{Case study 2 on IEEE 26-Bus test system with non-smooth cost function}

This case study comprises of 6 generation units, 26 buses and 46 transmission lines [29] and all the thermal units are within the ramp rate limits and prohibited zones. The data for this system is taken from the reference [29], [30] and the load demand required for this system taken as $P D=1263$. The transmission loss coefficient of the B matrix is determined as follows.

$$
\begin{aligned}
& B_{i j}=10^{-3} \cdot\left[\begin{array}{cccccc}
1.7 & 1.2 & 0.7 & -0.1 & -0.5 & -0.2 \\
1.2 & 1.4 & 0.9 & 0.1 & -0.6 & -0.1 \\
0.7 & 0.9 & 3.1 & 0.0 & -1.0 & -0.6 \\
-0.1 & 0.1 & 0.0 & 0.24 & -0.6 & -0.8 \\
-0.5 & -0.6 & -0.6 & -0.6 & 12.9 & -0.2 \\
-0.2 & -0.1 & -0.6 & -0.8 & -0.2 & 15.0
\end{array}\right] \\
& B_{i 0}=10^{-3} \cdot\left[\begin{array}{llllll}
-0.3908 & -0.1297 & -0.7047 & -0.0591 & 0.2161 & -0.6635
\end{array}\right] \\
& B_{00}=0.056
\end{aligned}
$$

Table 6 shows the performance comparison among the proposed algorithms, a particle swarm optimization (PSO) approach [29], a novel string based GA [12], standard genetic algorithm (GA) method [29], multiple task search algorithm (MTS) [13], and the simulated annealing (SA) method [13]. The simulation results of the proposed approach outperformed recent optimization methods presented in the 
literature in terms of solution quality and time convergence. The computational time of the proposed approach is reduced significantly in comparison to the other methods.

Table 6. Results of the minimum cost and power generation compared with global optimùization methods for 26-bus test system

\begin{tabular}{|c|c|c|c|c|c|c|c|}
\hline \multicolumn{2}{|c|}{$\begin{array}{l}\text { Generators } \\
\text { (MW) }\end{array}$} & \multirow{2}{*}{$\begin{array}{c}\text { SA [13] } \\
478.1258\end{array}$} & \multirow{2}{*}{$\begin{array}{c}\text { New-string } \\
\text { GA [12] } \\
446.7100\end{array}$} & \multirow{2}{*}{$\begin{array}{l}\text { GA [23] } \\
474.8066\end{array}$} & \multirow{2}{*}{$\begin{array}{l}\text { MTS [13] } \\
448.1277\end{array}$} & \multirow{2}{*}{$\begin{array}{l}\text { PSO [23] } \\
447.4970\end{array}$} & \multirow{2}{*}{$\begin{array}{c}\text { Our Approach } \\
448.0451\end{array}$} \\
\hline$P_{g 1}$ & Part1 & & & & & & \\
\hline$P_{g 2}$ & & 163.0249 & 173.0100 & 178.6363 & 172.8082 & 173.3221 & 172.0835 \\
\hline$P_{g 3}$ & Part2 & 261.7143 & 265.0000 & 262.2089 & 262.5932 & 263.4745 & 264.5932 \\
\hline$P_{g 4}$ & & 125.7665 & 139.0000 & 134.2826 & 136.9605 & 139.0594 & 134.9605 \\
\hline$P_{g 5}$ & Part3 & 153.7056 & 165.2300 & 151.9039 & 168.2031 & 165.4761 & 170.2452 \\
\hline$P_{g 6}$ & & 90.7965 & 86.7800 & 74.1812 & 87.3304 & 87.1280 & 85.2884 \\
\hline \multicolumn{2}{|c|}{ Total PG } & 1276.1339 & 1275.73 & 1276.03 & 1276.0232 & 1276.01 & 1275.20 \\
\hline \multicolumn{2}{|c|}{ Ploss (MW) } & 13.1317 & 12.733 & 13.0217 & 13.0205 & 12.9584 & 12.2160 \\
\hline \multicolumn{2}{|c|}{$\operatorname{Cost}[\$ / \mathrm{hr}]$} & 15461.10 & 15447.00 & 15459.00 & 15450.06 & 15450.00 & 15439 \\
\hline \multicolumn{2}{|c|}{ CPU time(s) } & - & 8.36 & - & 1.29 & 14.89 & 1.4380 \\
\hline
\end{tabular}

\subsection{Case study 3 on the IEEE 118-Bus}

To investigate the strength of the projected approach the algorithmic program was enforced and tested to the quality IEEE 118-bus model system (54 generators, 186 (line + transformer) and ninety nine loads). The system load is $4242 \mathrm{MW}$ and base MVA is $100 \mathrm{MVA}$. During this model, there are 54 generators and that they are consists of various 18 characteristic generators [25]. The projected approach is compared to the $\$ 64000$ Genetic algorithmic program projected in [25]. The results pictured in Table 6 show clearly that the projected approach provides far better results than the other technique. The distinction in generation value between these 2 studies $(6347.2 \$ / \mathrm{h}$ compared to $8278.9 \$ / \mathrm{h})$ and in real power loss $(106.788 \mathrm{MW}$ compared to $94.305 \mathrm{MW}$ ).

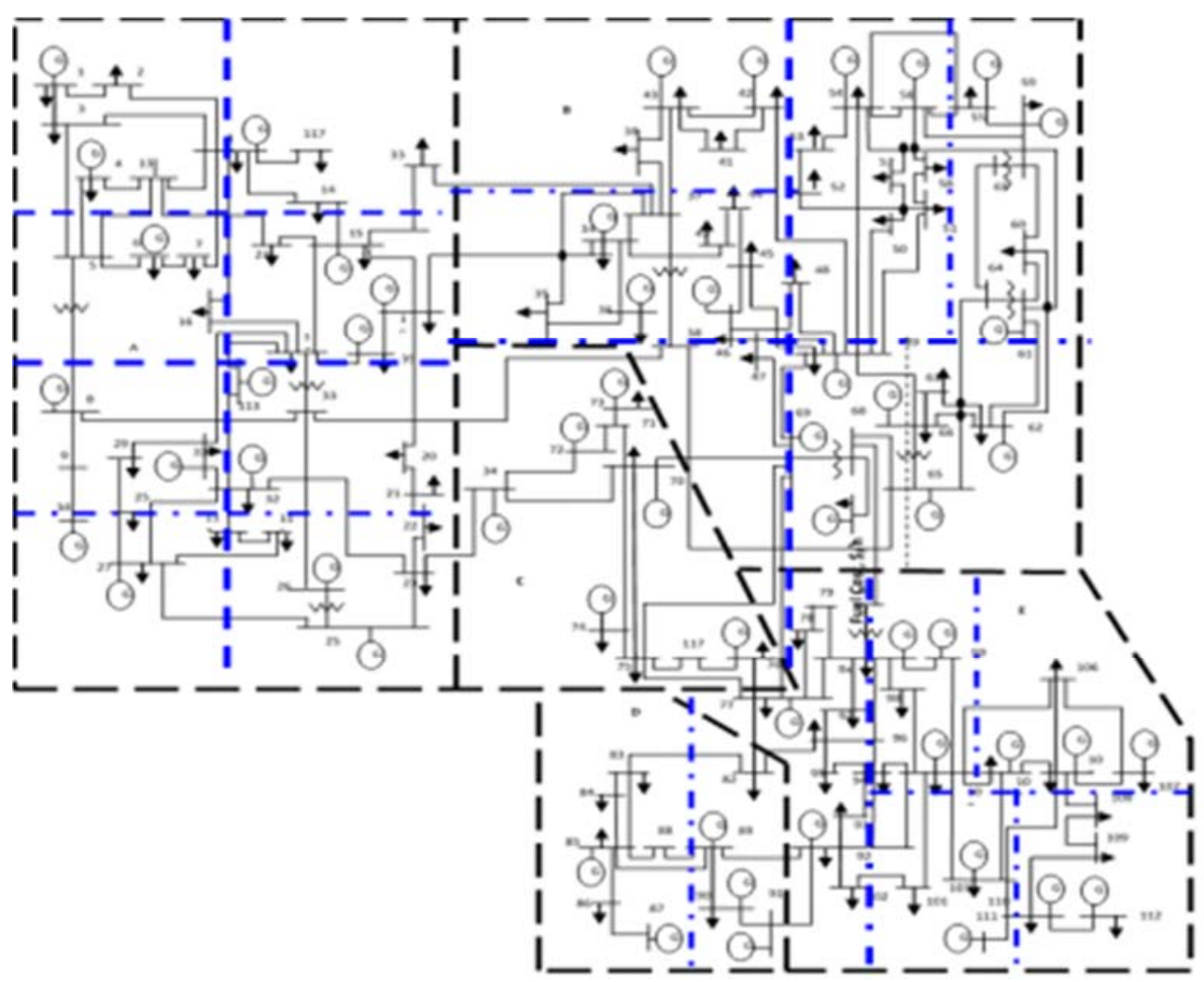

Figure 9. Topology of the IEEE 118-bus test system 
The optimum active powers ars bushed their secure limits values and are off from the physical constraints limits. The protection constraints also are checked for voltage magnitudes and angles. Reactive power designing [11], [12] applied within the second step based mostly in sensible fuzzy rules. Figure 9 show the topology the quality IEEE 118-Bus. Figure 10 shows that the reactive power generations are on their security limits; Figure 11 shows the reactive power changed between the SVC Compensators put in at crucial buses and also the network. Figure 12 demonstrates that the voltage profiles for all buses are increased based mostly in reactive power designing sub problem.

The convergence values of IEEE 118 bus system on multi objective basis is shown in above Figure 13. The variation with real power loss, reactive power loss, voltage profile and fuel cost for the standard IEEE 30 bus system with combined APO with AMO and APO is presented and it shows the importance of utilizing APO with AMO than APO.

The comparison Results of proposed method with GA for IEEE 118-Bus in terms of the Minimum Cost and Power Generation is shown in Table 7.

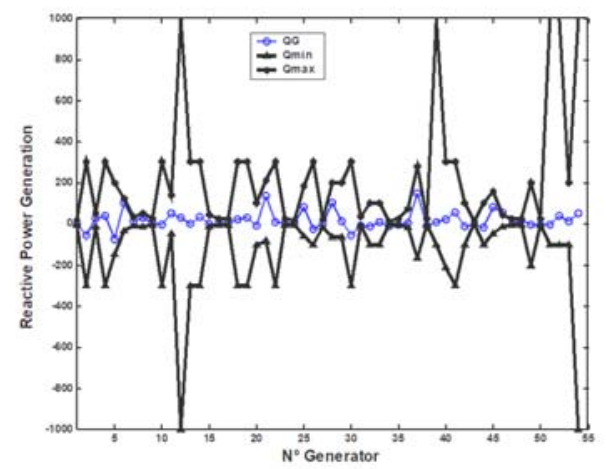

Figure 10. Reactive power generation of IEEE 118bus electrical network with shunt compensation $(\mathrm{pd}=4242 \mathrm{mw})$

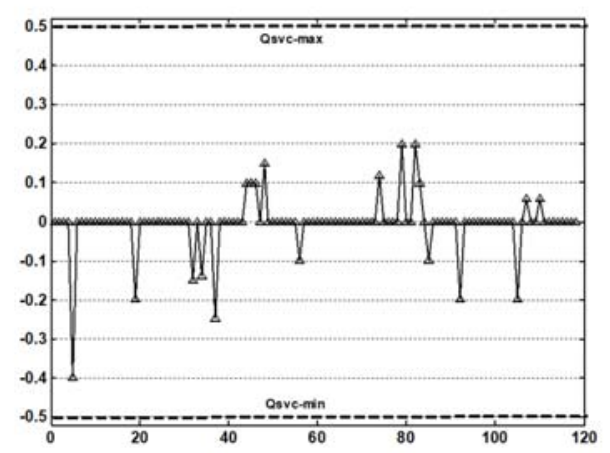

Figure 11. Reactive power compensation based SVC compensators exchanged with the IEEE 118bus electrical network $(\mathrm{pd}=4242 \mathrm{mw})$

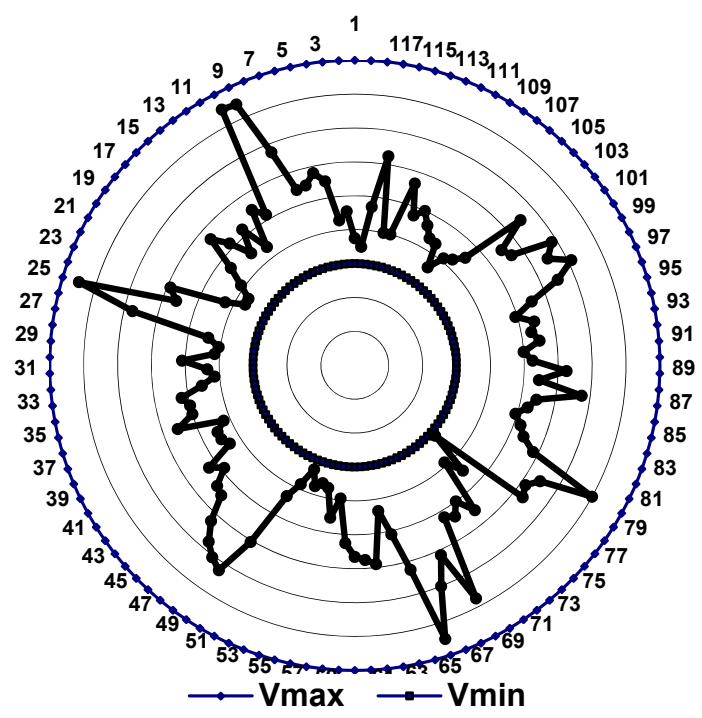

Figure 12. Voltage profiles of IEEE 118-bus electrical network 

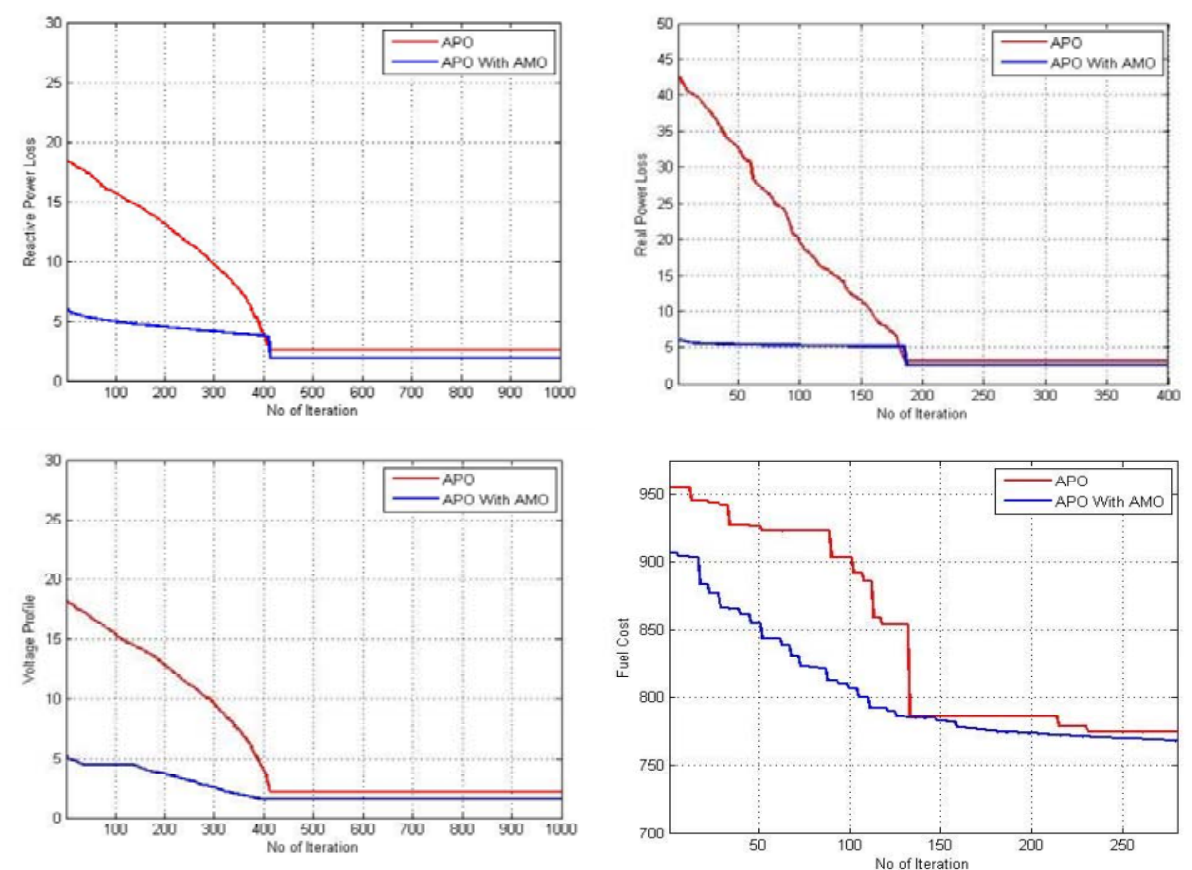

Figure 13. Convergence of IEEE 118 bus system

Table 7. Results of the minimum cost and power generation compared with GA for IEEE 118-bus

\begin{tabular}{|c|c|c|c|c|c|c|c|}
\hline Gen & Type & EPGA & GA [19] & Gen & Type & EPGA & GA [19] \\
\hline 1 & $\# 1$ & 10.840 & 11.9933 .603 & 65 & $\# 11$ & 402.60 & 456.61 \\
\hline 4 & $\# 1$ & 11.280 & 10.191 & 66 & \#11 & 120.06 & 134.99 \\
\hline 6 & $\# 1$ & 16.840 & 10.038 & 69 & $\# 12$ & 523.05 & 316.59 \\
\hline 8 & $\# 1$ & 21.380 & 162.0963 .06 & 70 & $\# 1$ & 26.700 & 24.148 \\
\hline 10 & $\# 2$ & 258.86 & 28.439 & 72 & $\# 1$ & 21.940 & 31.967 \\
\hline 12 & \#3 & 92.760 & 10.398 & 73 & $\# 1$ & 14.040 & 43.362 \\
\hline 15 & $\# 1$ & 10.000 & 10.023 & 74 & $\# 1$ & 25.480 & 10.14916 .45 \\
\hline 18 & $\# 1$ & 10.000 & 13.178 & 76 & $\# 1$ & 28.020 & 12.131 \\
\hline 19 & $\# 1$ & 10.780 & 282.02 & 77 & $\# 1$ & 15.820 & 445.55 \\
\hline 24 & $\# 1$ & 10.060 & 376.55 & 80 & $\# 13$ & 370.54 & 18.717 \\
\hline 25 & $\# 4$ & 289.98 & 29.683 & 85 & $\# 1$ & 47.260 & 44.402 \\
\hline 26 & $\# 5$ & 411.80 & 67.232 & 87 & $\# 14$ & 27.400 & 322.79 \\
\hline 27 & $\# 1$ & 13.700 & 14.144 & 89 & $\# 15$ & 392.38 & 20.24 \\
\hline 31 & \#6 & 43.100 & 12.912 & 90 & $\# 1$ & 10.000 & 21.206 \\
\hline 32 & $\# 1$ & 11.020 & 12.639 & 91 & $\# 1$ & 10.000 & 19.163 \\
\hline 34 & $\# 1$ & 12.160 & 66.505 & 92 & $\# 1$ & 10.000 & 10.161 \\
\hline 36 & $\# 1$ & 10.300 & 19.805 & 99 & $\# 1$ & 10.000 & 318.47 \\
\hline 40 & \#1 & 14.180 & 13.345 & 100 & $\# 16$ & 312.88 & 47.058 \\
\hline 42 & $\# 1$ & 15.100 & 217.8852 .24 & 103 & $\# 17$ & 82.840 & 39.387 \\
\hline 46 & \#7 & 73.420 & 14.431 & 104 & $\# 1$ & 10.000 & 18.515 \\
\hline 49 & $\# 8$ & 101.24 & 23.335 & 105 & $\# 1$ & 10.000 & 10.248 \\
\hline 54 & $\# 9$ & 40.820 & 59.497 & 107 & $\# 1$ & 40.820 & 10.554 \\
\hline 55 & $\# 1$ & 13.140 & 195.11 & 110 & $\# 1$ & 18.620 & 28.67 \\
\hline 56 & $\# 1$ & 14.520 & 43.015 & 111 & $\# 18$ & 56.280 & 10.833 \\
\hline 59 & $\# 10$ & 157.26 & & 112 & $\# 1$ & 12.060 & 22.311 \\
\hline 61 & $\# 10$ & 41.920 & & 113 & $\# 1$ & 11.340 & 28.272 \\
\hline 62 & $\# 1$ & 11.820 & & 116 & $\# 1$ & 10.380 & \\
\hline $\operatorname{Cost}(\$ / h r) t$ & & 6347.2 & 8278.9 & & & & \\
\hline Losses (MW) & & 106.788 & 94.305 & & & & \\
\hline
\end{tabular}

The comparison Results of proposed method with GA for IEEE 118-Bus in terms of the Minimum Cost and Power Generation is shown in Table 7. Thus the cost factor for EPGA is given by 6347.2 and Power generated is given by $106.788 \mathrm{MW}$ which is seen that far better than compared with the GA whose minimum cost is about 8278.9 which is comparatively higher than our proposed workwhich indicates our work as cost effective one and similarly generated power is of 94.305 which is far much lesser than the framework. 


\subsection{Result conclusion}

It is clearly shown that the results obtained from our framework implying Epga has better results. Initially, the comparison is done with $\mathrm{S}_{\mathrm{ga}}, \mathrm{E}_{\mathrm{ga}}, \mathrm{I}_{\mathrm{ep}}, \mathrm{F}_{\mathrm{ga}}$ and $\mathrm{M}_{\mathrm{de}}$ for justifying the Obtained results. Similarly, in order to verify the robustness, the proposed work is compared with $\mathrm{P}_{\text {sat }}$, Matpower.Then a brief comparison is done with GA for justifying the betterment of process. Also, it is made damn clear, that from the above figures and comparisons the clear knowledge and enhancement of process and importance of our proposed method. The simulation results show that the multi objective problem is solved efficiently by using our proposed APO with AMO algorithms than the existing methods. These make us to conclude that the proposed research work will be a better of choice to solve optimal power flow problem with multi objective function.

\section{CONCLUSION}

This article has conferred a unique HMOAPO algorithm and also the AMO algorithm to resolve the OPF problem in electrical power systems. These algorithms are not to optimize multi objective functions at the same time underneath the system constraints. The simulation results have verified the high performance of each algorithms for resolution the target operate strategy within the customary IEEE 30-bus system. Moreover, the DE algorithmic rule is employed to resolve multi-objective OPF issues with the assistance of the fuzzy-based Pareto front methodology. It will be completed that the proposed APO algorithm-based simulation results are competitive thereto of different recent optimization techniques. For an intensive verification, each algorithms area unit applied to an outsized facility, i.e., the quality IEEE 118-bus system. The simulation results have supported relevancy, potential, and effectiveness of those algorithms.

\section{REFERENCES}

[1] M.A. Abido, "Optimal power flow using particle swarm optimization," International Journal of Electrical Power and Energy Systems, vol. 24, no. 7, pp. 563-71, 2002.

[2] L.L. Lai, J.T. Ma, R. Yokoyama and M. Zhao, "Improved genetic algorithms for optimal power flow under both normal and contingent operation states," International Journal of electrical power and energy systems, vol. 19, no. 5, pp. 287-92, 1997.

[3] Jason Yuryevich and Kit Po Wong, "Evolutionary Programming Based Optimal Power Flow Algorithm," IEEE Transactions on power systems, vol. 14, no. 4, pp. 1245-50, 1999.

[4] Q.H. Wu and J.T. Ma, "Power system optimal reactive power dispatch using evolutionary programming," IEEE transactions on power systems, vol. 10, no. 3, pp. 1243-9, 1995.

[5] P.K. Hota, A.K. Barisal and R. Chakrabarti, "Economic emission load dispatch through fuzzy based bacterial foraging algorithm," International Journal of electrical power and energy systems, vol. 32, no. 7, pp. 794-803, 2010.

[6] A. Chatterjee, S.P. Ghoshal and V. Mukherjee, "Solution of combined economic and emission dispatch problems of power systems by an opposition-based harmony search algorithm," International Journal of electrical power and energy systems, vol. 39, no. 1, pp. 9-20, 2012.

[7] D.B. Das and C. Patvardhan, "New multi-objective stochastic search technique for economic load dispatch," IEEE Proceedings-Generation, Transmission and Distribution, vol. 145, no. 6, pp. 747-52, 1998.

[8] J. Nanda, Lakshman Hari and M.L. Kothari, "Economic emission load dispatch with line flow constraints using a classical technique," IEEE Proceedings-Generation, Transmission and Distribution, vol. 141, no. 1, pp. 1-0, 1994.

[9] P.K. Hota, R. Chakrabarti and P.K. Chattopadhyay, "Economic emission load dispatch through an interactive fuzzy satisfying method," Electric power systems research, vol. 54, no. 3, pp.151-7, 2000.

[10] S. Titus and A. Ebenezer Jeyakumar, "A Hybrid EP-PSO-SQP Algorithm for Dynamic Dispatch Considering Prohibited Operating Zones," Electric power components and systems, vol. 36, no. 5, pp. 449-67, 2008.

[11] Pathom Attaviriyanupap, Hiroyuki Kita, Eiichi Tanaka and Jun Hasegawa, "A Hybrid EP and SQP for Dynamic Economic Dispatch with Nonsmooth Fuel Cost Function," IEEE transactions on power systems, vol. 17, no. 2, pp. 411-6, 2002.

[12] Amita Mahor, Vishnu Prasad and Saroj Rangnekar, "Economic dispatch using particle swarm optimization: A review," Reviewable and Sustainable energy reviews, vol. 13, no. 8, pp. 2134-41, 2009.

[13] Tahir Nadeem Malik, Azzam ul Asar, Mudasser F. Wyne and Shakil Akhtar, "A new hybrid approach for the solution of nonconvex economic dispatch problem with valve-point effects," Electric power systems research, vol. 80, no. 9, pp. 1128-36, 2010.

[14] V. Keshri, and P. Gupta, "Measurement and Analysis of Power in Hybrid System," Indonesian Journal of Electrical Engineering and Informatics (IJEEI), vol. 4, no. 4, pp.256-263, 2016.

[15] G.G. Raju, and S.M. Ali, "Fuzzy Based Gain Scheduled PI Controller for an Isolated Wind Diesel Hybrid Power System,” Bulletin of Electrical Engineering and Informatics, vol. 1, no. 3, pp.213-224, 2012.

[16] H. Shahinzadeh, S.M. Nasr-Azadani, and N. Jannesari, "Applications of particle swarm optimization algorithm to solving the economic load dispatch of units in power systems with valve-point effects." International Journal of Electrical and Computer Engineering, vol. 4, no. 6, pp.858, 2014.

Int J Pow Elec \& Dri Syst, Vol. 10, No. 1, March 2019: 486 - 503 
[17] H. Abniki, M. Abolhasani, and M.E. Kargahi, "Vector Control Analysis of Doubly-Fed Induction Generator in Wind Farms," Energy and Power, vol. 3, no. 2, pp.18-25, 2013.

[18] H.R. Mohammadi, and A. Akhavan, "A New Control Method for Grid-Connected PV System Based on Quasi-ZSource Cascaded Multilevel Inverter Using Evolutionary Algorithm," International Journal of Power Electronics and Drive Systems (IJPEDS), vol. 6, no. 1, pp.109, 2015.

[19] J. Zhu, W.X. Pan, and Z.P. Zhang, "Embedded Applications of MS-PSO-BP on Wind/Storage Power Forecasting," Telkomnika, vol. 15, no. 4, 2017.

[20] Po-Hung Chen and Hong-Chan Chang, "Large-scale economic dispatch by genetic algorithm," IEEE transactions on power systems, vol. 10, no. 4, pp. 1919-26, 1995.

[21] G. Anastasios Bakirtzis, N. Pandel Biskas, E. Christoforos Zoumas and Vasilios Petridis, "Optimal Power Flow by Enhanced Genetic Algorithm," IEEE transactions on power systems, vol. 17, no. 2, pp. 229-36, 2002.

[22] M. Basu, "Hybridization of Artificial Immune Systems and Sequential Quadratic Programming for Dynamic Economic Dispatch," Electric power components and systems, vol. 37, no. 9, pp. 1036-45, 2009.

[23] V. Ravikumar Pandi and Bijaya Ketan Panigrahi, "Dynamic economic load dispatch using hybrid swarm intelligence based harmony search algorithm," Expert systems with applications, vol. 38, no. 7, pp. 8509-14, 2011.

[24] Shanhe Jiang, Zhicheng and Yanxia Shen, "A novel hybrid particle swarm optimization and gravitational search algorithm for solving economic emission load dispatch problems with various practical constraints," International Journal of Electrical Power \& Energy Systems, vol. 55, pp. 628-44, 2014.

[25] Aniruddha Bhattacharya and Pranab Kumar Chattopadhyay, "Hybrid Differential Evolution with BiogeographyBased Optimization for Solution of Economic Load Dispatch," IEEE transactions on power systems, vol. 25, no. 4, pp. 1955-64, 2010.

[26] Jiejin Cai, Qiong Li, Lixiang Li, Haipeng Peng and Yixian Yang, "A hybrid CPSO-SQP method for economic dispatch considering the valve-point effects," Energy Conversion and Management, vol. 53, no. 1, pp. 175-81, 2012.

[27] Behnam Mohammadi-Ivatloo, Abbas Rabiee and Alireza Soroudi, "Nonconvex Dynamic Economic Power Dispatch Problems Solution Using Hybrid Immune-Genetic Algorithm," IEEE Systems Journal, vol. 7, no. 4, pp. 777-85, 2013.

[28] K. Vaisakh, P. Praveena, S. Rama Mohana Rao and Kala Meah, "Solving dynamic economic dispatch problem with security constraints using bacterial foraging PSO-DE algorithm," International Journal of electrical power and energy systems, vol. 39, no. 1, pp. 56-67, 2012.

[29] D.F. Spears, W. Kerr, W. Kerr, S. Hettiarachchi, “An overview of physicomimetics," Lect Notes Comput Sci-State Art Ser. Vol. 3324, pp.84-97, 2005.

[30] L.P. Xie, J.C. Zeng, "A global optimization based on physicmimetics framework," In: Proceedings of the first ACM/SIGEVO summit on genetic and evolutionary computation. New York, USA, pp. 609-16, 2009.

[31] L. Xie, J. Zeng, Z. Cui, "Using artificial physics to solve global optimization problems," In: 8th IEEE International Conference on Cognitive Informatics (ICCI). Kowloon, Hong Kong, pp. 502-8, 2009.

[32] L.P. Xie, J.C. Zeng, "The performance analysis of artificial physics optimization algorithm driven by different virtual forces," ICIC Express Lett. Vol. 4, no. 1, pp. 239-44, 2010.

[33] L. Xie, J. Zeng, "An extended artificial physics optimization algorithm for global optimization problems," In: IEEE fourth International Conference on Innovative Computing, Information and Control (ICICIC). Kaohsiung, Taiwan, pp. 881-4. 